\title{
El cuerpo de Eva en Tomás de Aquino
} (The body of Eva in Thomas Aquinas)

\author{
GUSTAVO CARLOS BITOCCHI \\ UNSTA Universidad del Norte “Santo Tomás de Aquino”, Buenos Aires \\ UA Universidad Austral, Buenos Aires \\ bitocchi@gmail.com \\ ORCID: 0000-0002-1693-7354
}

Resumen. La constitución del primer cuerpo femenino o el cuerpo de Eva tiene planteos que conllevan problemáticas metafísicas y físicas diversas que han derivado en consecuencias sociales y culturales para la mujer que han atravesado los siglos y llegan hasta la actualidad. La no existencia de progenitores, exige del Aquinate respuestas que exceden lo meramente antropológico y biológico y le conduce a la búsqueda de respuestas más profundas, que, muchas veces están entrelazadas con afirmaciones de carácter teológico y religioso. Tomás de Aquino brinda respuestas de razón aunque el trasfondo sea de fe, e inclusive, con interpretaciones literales de las Sagradas Escrituras actualmente ya abandonadas. No obstante esto, el Aquinate realiza un verdadero esfuerzo intelectual para encontrar respuestas en un ámbito meramente racional pues la materialidad del cuerpo de la primera mujer trae dificultades para su dilucidación y entendimiento. Como en otras partes de su extensa obra, Tomás de Aquino, sigue las obras biológicas y físicas de Aristóteles. Si bien el fondo es aristotélico está en consonancia con el trasfondo cristiano, pues, el Aquinate muestra su extraordinaria capacidad 
de síntesis entre la fe recibida y la razón argumentada, entre la revelación (y en especial las Sagradas Escrituras en este caso) y los principios de razón.

Palabras clave: corporeidad; materia; hombre; Adán; mujer; feminismo.

Abstract. The constitution of the first female body or the body of Eva presents several physical and metaphysical problems, problems that have gone through the centuries and reach the present, generating social and cultural consequences for women. The non-existence of parents demands from Aquino answers that go beyond the anthropological and biological and lead to the search of philosophical answers intertwined with the theological ones. Thomas Aquinas provides rational answers although the background is of faith, and even, with literal interpretations of the Sacred Scriptures now abandoned. The Aquinate makes an intellectual effort to find answers in a rational field because the matter of the body of the first woman brings difficulties for its elucidation and understanding. As in other parts of his extensive work, Thomas Aquinas, follows the biological and physical works of Aristotle. Although the Aristotelian background is in line with Christian thought, Aquinas shows his extraordinary capacity for synthesis between the faith received and reason argued, between revelation (and especially the Holy Scriptures in this case) and the principles of reason.

Keywords: body; matter; man; Adam; woman; feminism.

\section{Introducción}

El cuerpo humano en Tomás de Aquino puede abordarse desde una doble vertiente: desde una perspectiva en que el cuerpo surge por creación o desde otra donde el cuerpo se origina por generación. A su vez, cada vertiente se refiere tanto al varón como a la mujer. Inclusive, cabe agregar en la segunda vertiente la temática del embrión humano. Por otra parte, para completar el panorama desde lo sobrenatural, ha de agregarse la consideración del cuerpo del Cristo y del cuerpo del resucitado, tanto del bienaventurado como del condenado, como así también la del cuerpo del hombre antes del pecado original. Aquí, en este estudio y análisis, se ha de tratar el cuerpo de la mujer que se suscita por creación desde los textos del Aquinate, pero es claro que, para un estudio integral conviene complementarlo con el resto de los abordajes. 


\begin{tabular}{|c|c|c|c|c|c|c|c|}
\hline \multicolumn{8}{|c|}{ EL CUERPO HUMANO NATURAL EN TOMÁS DE AQUINO } \\
\hline \multicolumn{4}{|c|}{ POR CREACIÓN } & \multicolumn{4}{|c|}{ POR GENERACIÓN } \\
\hline \multicolumn{2}{|c|}{ I } & \multicolumn{2}{|r|}{$\|$} & \multicolumn{2}{|l|}{ III } & \multicolumn{2}{|c|}{ IV } \\
\hline \multicolumn{2}{|c|}{ PRIMER VARÓN: ADÁN } & \multicolumn{2}{|c|}{$\begin{array}{l}\text { PRIMERA MUJER: } \\
\text { EVA }\end{array}$} & \multicolumn{2}{|c|}{$\begin{array}{c}\text { EL RESTO DE LOS SUJETOS HUMANOS: } \\
\text { VARONES Y MUJERES }\end{array}$} & \multicolumn{2}{|c|}{ EL CRISTO } \\
\hline VIRTUD & VIRTUD & VIRTUD & VIRTUD & VIRTUD & VIRTUD & VIRTUD & VIRTUD \\
\hline ACTIVA & PASIVA & ACTIVA & PASIVA & ACTIVA & PASIVA & ACTIVA & PASIVA \\
\hline \multirow{2}{*}{ Dios } & \multirow{2}{*}{$\begin{array}{c}\text { Limo de la } \\
\text { tierra } \\
\text { (cuatro } \\
\text { elementos) } \\
\text { - } \\
\text { Ex limo terrae }\end{array}$} & \multirow{2}{*}{ Dios } & \multirow{2}{*}{$\begin{array}{c}\text { Materia del varón: } \\
\text { "Costilla del } \\
\text { varón (materia } \\
\text { preexistente) por } \\
\text { adición de algo (una } \\
\text { materia) exterior" } \\
\text { - } \\
\text { Ex viro; } \\
\text { De costa viri }\end{array}$} & $\begin{array}{c}\text { La virtud formativa de la } \\
\text { simiente del varón } \\
\text { (en cuanto genera alma } \\
\text { vegetativa/alma sensitiva) y }\end{array}$ & \multirow{2}{*}{$\begin{array}{l}\text { Menstruo de la } \\
\text { mujer }\end{array}$} & \multirow{2}{*}{ Dios } & \multirow{2}{*}{$\begin{array}{l}\text { Menstruo de } \\
\text { la mujer }\end{array}$} \\
\hline & & & & $\begin{array}{c}\text { Dios por creación } \\
\text { (en cuanto infunde el alma } \\
\text { racional) }\end{array}$ & & & \\
\hline $\begin{array}{l}\sin \\
\text { varón }\end{array}$ & $\begin{array}{l}\sin \\
\text { mujer }\end{array}$ & $\begin{array}{l}\text { con varón } \\
\text { pero sin } \\
\text { simiente }\end{array}$ & $\begin{array}{l}\sin \\
\text { mujer }\end{array}$ & $\begin{array}{l}\text { con } \\
\text { varón }\end{array}$ & $\begin{array}{l}\text { con } \\
\text { mujer }\end{array}$ & $\begin{array}{c}\sin \\
\text { varón }\end{array}$ & $\begin{array}{l}\text { con } \\
\text { mujer }\end{array}$ \\
\hline
\end{tabular}

Es un tema muy poco investigado y no hay estudios específicos al respecto. No obstante esto, es encomiable la voluntad y energía del Aquinate por buscar una salida filosófico-racional al dato revelado, siempre en aras de establecer una armonía entre la fe y la razón. Esta salida la intenta tanto desde la cosmología como de la teología natural. La resolución entraña un vivo ejemplo para todo pensador cristiano: buscar salidas y soluciones con energía argumental para lograr una conformidad entre el dato revelado y el pensamiento filosófico.

Es un tema muy grave, ya que muchas de las afirmaciones filosóficas respecto a la naturaleza del cuerpo de la mujer, han originado múltiples consecuencias no menos graves en otros planos a través de la historia. Así, la mujer ha de tener, por su condición y constitución corpórea, un status ontológico determinado que influirá en su situación respecto del varón, del matrimonio, de los hijos, de la sociedad en general, e inclusive de Dios; en otras palabras, su status corpóreo influirá en su modus vivendi. La gravedad, delicadeza e importancia de las consecuencias de la noción ontológica 
de la mujer estimulan a ver y profundizar la posición del Aquinate que tanto ha influido en el pensamiento filosófico, cristiano y occidental con relación a la mujer. No es un tema que Tomás de Aquino toma sin dejar de sacar consecuencias de toda índole en diversas partes de su filosofía; por el contrario, la contundencia de sus consideraciones, fuertemente influidas por su época. En lo que sigue, se han de buscar los principios orientadores de sus afirmaciones, para así, llegar a obtener sus supuestos principales y fundantes que permitan una mayor comprensión del problema que se está tratando. Por otra parte, la consideración del cuerpo femenino permite una mejor comprensión de cómo está constituido el cuerpo del varón y a la inversa, se puede llegar a una mayor profundización de lo corpóreo masculino investigando en la concepción del cuerpo de la mujer. El entramado lógico y el trabajo de síntesis del Aquinate permite esta forma de investigación, pues nada está puesto al acaso sin que tenga relación con otras partes de su pensamiento, como ocurre en lo tocante al tema que se está tratando.

Como se ve, si bien el tema tiene consecuencias que sobrepasan el marco filosófico, aquí se estudiará y analizará, desde el pensamiento de Tomás de Aquino, exclusivamente el aspecto cosmológico y teológico-natural (o filosófico) de la problemática, en donde la influencia del pensamiento de Aristóteles en el Aquinate es notable y abundante. Se deja para posteriores estudios las consecuencias que exceden este marco tanto por su complejidad como riqueza de matices y conclusiones.

\section{A partir de un varón}

La literalidad de las Escrituras exige al Aquinate considerar que el cuerpo de la primera mujer, Eva, no se da por generación sino que se toma (o se forma) a partir de alguna materia determinada (Gilson 1951, 248). Tomás de Aquino debe buscar respuestas en la consideración de la materia en sí, de sus propiedades y atributos, es decir, tiene que indagar cuán plástica y cuán maleable es su constitución. También ha de profundizar e investigar sobre el alcance infinito de la omnipotencia divina. El Aquinate está, en sus argumentos, en una delicada y fina tensión entre dos puntos a primera 
vista opuestos: por un lado, consideraciones sobre la materialidad y, por el otro, consideraciones sobre el poder de la virtus divina; está entre la física y la teología natural para encontrar respuestas antropológicas.

El cuerpo de la primera mujer se toma de una materia, y sobre ella habrá un poder omniabarcante que brinda respuestas que, tal vez, un oído moderno no quiera oír o no pueda sufrir. El oído moderno se desacostumbró de explicaciones metafísicas y de teología natural (o teodicea) que incluyan posturas creacionistas. Las elucidaciones que tienen relación con el concepto de creación no suelen aceptarse ni siquiera como hipotéticas. No obstante, las respuestas brindadas por Tomás de Aquino merecen un oído dispuesto.

El cuerpo del 'primer' varón es creado directamente por Dios, es decir, viene de Dios como de su principio. En cambio, el cuerpo de la primera mujer (hembra), a diferencia de los demás animales perfectos (Rossi 1991, 108), fue conveniente que fuera formado o tomado del varón ("ex viro") como de su principio (Tomás de Aquino, Sum. Theol., I, q. 92, a. 2 co.). No dice que fuese necesario que así debiera hacerse, no pudiendo ser de otra manera, sino que es beneficioso y oportuno para un fin. Por esto, que se haya tomado del varón es concorde con un intento de síntesis con la revelación: Es conveniente sostener que la mujer proviene de otro, de un varón, es decir, hay motivos que permiten concordar con los elementos recibidos por la fe. Hay razones oportunas y convenientes para sostener que la mujer fuera tomada del varón.

$1^{\circ}$ ) Para dar más dignidad al primer varón, pues así, éste resultaría el principio de toda su especie, así como Dios es el principio de todo el universo (Tomás de Aquino, Super Sent., lib. 2, d. 18, q. 1, a. 1, ad 1; Sum. Theol., I, q. 92, a. 2 co.).

$2^{\circ}$ ) Para que, al saber que ha sido tomado de él, el varón amase más a la mujer y se le uniera de modo indisoluble (Tomás de Aquino, Sum. Theol., I, q. 92, a. 2 co.). Motivo que influye directamente sobre la naturaleza y propiedades intrínsecas del matrimonio.

$3^{\circ}$ ) Para que en las acciones de la vida doméstica, en las que hay algunas propias del varón y otras propias de la mujer, quede manifiesto que el varón es cabeza de la mujer (Tomás de Aquino, Super Sent., lib. 2, d. 18, q. 1, a. 1 , ad 1); pero también para significar que entre ellos hay una unión social 
donde queda excluido el desprecio y el sometimiento servil por parte del varón sobre la mujer, ya que no fue tomada de la cabeza ("ex capite”) ni de los pies ("ex pedibus") del varón, aunque sostiene claramente que la mujer no debe dominar sobre el varón (Tomás de Aquino, Sum. Theol., I, q. 92, a. 3 co.). Además, Tomás de Aquino refiere que en el libro VIII de la Ética de Aristóteles se dice:

Los hombres se unen no sólo para engendrar hijos, sino también para proveer los demás menesteres de la vida, ya que se reparten los oficios, y así el varón como la mujer tienen oficios diferentes. Haciendo, pues, cada uno de ellos su propio oficio, se valen el uno al otro, en lo que a los dos toca comúnmente (Aristóteles, Ética, Libro VIII, capítulo XII, 1162a).

Tomás de Aquino, en referencia al texto citado del Estagirita y, con relación a la unión social entre el varón y la mujer, señala que "además de esto en el texto se asignan otras dos razones que son por sí evidentes” (Tomás de Aquino, Super Sent., lib. 2, d. 18, q. 1, a. 1, ad 1): una, que la amistad entre varón (esposo) y la mujer (esposa) puede darse con dulzura y en utilidad común; y otra, que el trato del varón 'con respecto a la mujer' es más considerado que cualquier otro (Cfr. Aristóteles, Ética, Libro VIII, capítulo XII, in finem). Además, el Aquinate afirma que el varón no debe despreciar a la mujer como si fuera su sierva, porque no ha sido tomado su cuerpo de sus pies (“ex pedibus”) (Tomás de Aquino, Sum. Theol., I, q. 92, a. 3 co.).

Añade Tomás otro motivo rigurosamente religioso, que no obstante influye fuertemente en la consideración de los otros tres: para que se signifique que Cristo es principio de la Iglesia. Este último motivo lo establece el Aquinate a partir de una analogía muy importante en el contexto del pensamiento medieval: así como el varón es principio de la mujer, Cristo es principio de la Iglesia, y esta es la razón sacramental, oportuna y conveniente, para sostener que la mujer fuera tomada del varón (Tomás de Aquino, Sum. Theol., I, q. 92, a. 3 co.)

En síntesis, el cuerpo de la primera mujer fue tomado del cuerpo del primer varón y esto fue muy conveniente y adecuado: y así, si bien el cuerpo de Adán o ‘adánico’ surge de Dios por creación, el cuerpo de Eva o 'évico’ 
viene de Adán, de un varón. Viene de una parte corpórea específica de Adán: no de la cabeza ni de los pies, sino de un costado, es decir, fue conveniente que el cuerpo de la mujer fuera formado de una costilla del varón (Tomás de Aquino, Sum. Theol., I, q. 92, a. 2 co.; a. 3 co.).

\section{Desde una costilla del varón}

El cuerpo del primer varón fue creado a partir de una materia determinada y preexistente: el limo de la tierra (ex limo terrae). Así, en el cuerpo del varón (y en cualquier otro cuerpo) se encuentran los cuatro elementos de la física aristotélica en las debidas proporciones y con la complexión adecuada. En cambio, el cuerpo de la mujer surge a partir de otra materia: una costilla del varón (de costa viri) y también se encuentran en ella (la costilla) estos cuatro elementos. La virtus divina (Dios) a partir de una materia específica preexistente, el limo de la tierra o una costilla, crea el cuerpo del varón o produce el de la mujer. Así, Dios produce el cuerpo femenino, pero la costilla parece insuficiente en cuanto a sus dimensiones. Por esto, el Aquinate considera que la virtus divina, el poder infinito de Dios, podría suplir lo cuantitativo adicionando algo (material) exterior a la materia de la costilla.

La materia es aquello de lo cual y en lo cual está hecha una cosa. Las cosas o realidades están determinadas esencial o naturalmente; y esta determinación sigue un itinerario también determinado dentro de una especie. Esta determinación resulta del fluir propio del ímpetu de su propia virtus natural, pues ésta tiene una direccionalidad específica. Pero, por el contrario, la virtus divina puede hacer realidades de la misma especie como el varón del limo de la tierra y la mujer de la costilla del varón (Tomás de Aquino, Sum. Theol., I, q. 92, a. 2, ad 2; cfr. Argüello 2005, 48 ss.). Por esto, fue conveniente que los primeros principios se instituyeran en las naturalezas por virtud sobrenatural.

La institución del primer cuerpo femenino se puede entender, ya con respecto a cómo se va haciendo o instituyendo, o ya con respecto a las propiedades que de él se siguen. Que el primer cuerpo femenino fuera hecho a partir de una costilla varonil es algo que se aparta de la virtus 
de la naturaleza (Tomás de Aquino, Super Sent., lib. 2, d. 18, q. 1, a. 1 co.). Así, entonces, el cuerpo évico no puede darse del primer modo, porque no procede ni se hace de principios naturales, como en el caso del cuerpo de la mujer (no évico), sino que en el primer cuerpo femenino estos principios naturales no se conjugan para instituirlo ni para constituirlo. Como esto no es posible, convino y fue oportuno que los primeros principios de naturaleza en este primer cuerpo femenino se instituyeran y constituyeran por parte de la virtus divina (Tomás de Aquino, Super Sent., lib. 2, d. 18, q. 1, a. 1 ad 5).

El Aquinate afirma, pues, que sólo Dios, autor o institutor de naturaleza es capaz de producir un cuerpo femenino sin tener en cuenta el orden natural. Esto lo toma de Agustín de Hipona: "Formar o edificar para que la mujer exista, no lo puede hacer (nadie) sino (sólo) Dios, por el que la naturaleza del universo subsiste” (Tomás de Aquino, Sum. Theol., I, q. 92, a. 4 sc.); "Sólo Dios, institutor de la naturaleza, puede producir el ser a las cosas prescindiendo de orden natural. De donde se sigue que sólo Dios puede formar al varón del polvo de la tierra y a la mujer de una costilla de varón” (Tomás de Aquino, Sum. Theol., I, q. 92, a. 4 co.).

La virtus divina toma esa porción de materia presente en el varón, es decir, una costilla, con toda la literalidad que esto conlleva. Como se dijo, esa porción de materia no parece suficiente cuantitativamente, y esta insuficiencia debe resolverse. Pedro Lombardo ya había dado una solución al respecto, y el Aquinate la refiere en su Comentario a las Sentencias, pero sin nombrarlo explícitamente. La postura de Pedro Lombardo, a juicio de Tomás de Aquino, es imposible e inviable. Pedro Lombardo sostenía que el cuerpo de la mujer fue hecho sin adición material externa alguna, (del mismo modo que la multiplicación de los panes, pues estos se multiplicaron en sí mismos): "Si para completar el cuerpo de la mujer Dios hubiera añadido un aumento extrínseco, éste sería mayor que la costilla. Por lo cual se debería decir que el cuerpo de la mujer fue hecho más bien de aquel añadido que de la costilla". Y así, Pedro Lombardo sostiene: "El cuerpo de la mujer fue hecho de la sola sustancia de la misma costilla, sin ningún añadido extrínseco, multiplicada en sí misma por el poder divino" como la 
multiplicación de los panes (Tomás de Aquino, Comentario a las Sentencias de Pedro Lombardo, 527).

En la concepción de Pedro Lombardo, y en la de su contemporáneo Hugo de San Víctor, el adicionar o añadir materia a la costilla extraída del cuerpo varonil o una nueva creación (Tomás de Aquino, Super Sent., lib. 2, d. 18, q. 1, a. 1 co.), resulta inapropiado porque podría decirse que el cuerpo de la primera mujer fue hecho más bien de ese agregado material que de la costilla.

La problemática de la multiplicación de la materia puede plantearse bajo dos respectos: $1^{\circ}$ ) Sin adición de materia, y aquí, por lo tanto, debe considerarse como la costilla se transforma en el cuerpo de las primera mujer. Podría ser tal vez por una transformación sustancial o esencial, es decir, que la costilla 'se haga algo que antes no era' (un cuerpo de mujer), pero aun así no se resuelve lo cuantitativo, por eso, no parece posible sin adición de materia. O podría ser por rarefacción, proceso inverso al de la condensación dentro de la física aristotélica. La rarefacción indicaría que esta costilla crecería hasta alcanzar la cantidad necesaria para que obtenga la disposición material suficiente y pueda darse el primer cuerpo de mujer. Pero esta rarefacción consiste en una dilatación tal de la materia que este cuerpo femenino sería más sutil que el aire. Y esto no parece conveniente. $2^{\circ}$ ) Con adición de materia, es decir, añadiendo una materia exterior a la costilla misma, es decir, es necesario que bajo la forma del cuerpo femenino haya una cantidad de materia 'que antes no estaba' bajo la forma de la costilla. Pero esto requiere crear una materia absolutamente nueva o partir de una materia preexistente. No puede ser absolutamente novedosa pues se toma de una materia preexistente: la costilla del varón.

\section{Los inconvenientes para el cuerpo de Adán}

Se puede decir que el cuerpo de la primera mujer se instituye por el autor de la naturaleza (Dios), tomando un trozo de materia preexistente, la costilla de un varón. A ésta agrega (o adiciona) una materia exterior para completar y resolver el problema cuantitativo (Tomás de Aquino, Super Sent., lib. 2, d. 18, q. 1, a. 1 co.; Sum. Theol., I, q. 92, a. 3 ad 1). Pero aún queda una objeción: 
cada cosa ha de denominarse según la parte mayor y aquí, la parte mayor, sería el agregado material. El Aquinate responde:

El cuerpo de la mujer se hizo de la costilla por adición de algo exterior; aunque no se debe decir que el cuerpo de la mujer se hizo de aquel añadido, aunque sea mayor en cantidad, pues aquel añadido no entró en la materia de la mujer sino mediante la costilla, del mismo modo que se dice que el menstruo es la materia del embrión, aunque haga falta que el cuerpo del embrión adquiera mayor cantidad a partir de los alimentos transformados (Tomás de Aquino, Super Sent., lib. 2, d. 18, q. 1, a. 1 ad 2. Cfr. Sum. Theol., I, q. 92, a. 3, ad 1).

Se ha tratado el problema por parte del objeto u objetivamente, es decir, por parte de Eva: dónde, cómo y con qué se constituyó materialmente su cuerpo. Pero ahora, 'a consecuencia' de la existencia de este cuerpo évico, hay tres asuntos que considerar por parte del sujeto o subjetivamente, es decir, desde Adán. Así, éste, sufre o padece tres inconvenientes. Uno primero plantea un Adán que queda incompleto corpóreamente; uno segundo se refiere al posible dolor que sufrió en esta pérdida; y otro tercero es de índole ética. Como puede verse, la atención recae ahora sobre el sujeto adánico.

El primer inconveniente. La temática que se está tratando puede tener dos aristas a considerar: por un lado, la formación del cuerpo 'évico' a partir de la costilla del primer varón; y por otro lado, la incompletitud del cuerpo adánico resultante de la extracción de una de sus costillas, es decir, la falta de una parte material que le es propia por definición y le es dada por creación, es decir, deja de tener lo que el infinito poder divino (virtus divina) concibió y quiso desde toda la eternidad providentemente en cuanto a su constitución e institución. Por esto, siendo lo perfecto lo que está completo, terminado y finalizado, el cuerpo adánico, a consecuencia de la existencia del 'évico', resulta de algún modo imperfecto y disminuido, ya que la costilla no era algo superfluo en su ser, pues nada hay superfluo en las obras divinas. Así pues, surgen dos problemas: uno antropológico: se deja un cuerpo imperfecto para que surja otro; otro metafísico (o de teología natural): parece que en las cosas creadas hay cosas superfluas.

El Aquinate, en primer lugar, afirma categóricamente que "la costilla era de la perfección de Adán”. Para poder resolver esta problemática distingue, 
por un lado, que la costilla era de la perfección de Adán en cuanto éste era el principio de la especie; pero, por otro lado, esta costilla no lo era en cuanto al individuo. En otras palabras, la costilla era superflua e innecesaria para el individuo (adánico), pero necesaria para la conservación de la especie humana, ya que sin ella la mujer no hubiese existido, y si la mujer no hubiese existido, no se hubiese seguido generación alguna ni perpetuado la especie. El Aquinate pone como ejemplo la simiente del varón y establece una analogía: así como la simiente es superflua para el individuo, pero necesaria para la conservación de la especie, así la costilla es superflua para Adán pero necesaria para la conservación del género humano (Tomás de Aquino, Super Sent., lib. 2, d. 18, q. 1, a. 1 ad 3. Y cfr. Tomás de Aquino, Sum. Theol., I, q. 92, a. 3 ad 2).

Un segundo inconveniente. El Aquinate entiende que es un hecho que no puede haber división sin dolor y el cuerpo del primer varón sufrió y padeció división corporal. Tomás de Aquino resuelve rápidamente que "lo que está ordenado a la conservación de la especie, no sólo se separa sin dolor sino incluso con placer; y por eso no es preciso que sintiera dolor en la separación de aquella costilla". O también porque, siguiendo a Pedro Lombardo, "hay que decir que se hizo por virtus divina, de modo que, milagrosamente, no sintiera dolor por la herida" (Tomás de Aquino, Super Sent., lib. 2, d. 18, q. 1, a. 1 ad 4. Y cfr. Tomás de Aquino, Sum. Theol., I, q. 92, a. 3 ad 2 y ad 3). Como se ve, la explicación de razón no es aséptica a los prolegómenos de fe.

El tercer inconveniente. La condición femenina, con todo lo corpóreo que en esta expresión está implicado, es ocasión de pecado para este primer sujeto varón. El Aquinate resuelve el inconveniente diciendo que "si Dios hubiera quitado todas las cosas que sirvieran al hombre de ocasión de pecado, quedaría imperfecto este mundo", y "no es justo destruir el bien común para evitar un mal particular, sobre todo que Él es poderoso para ordenar todos los males al bien” (Tomás de Aquino, Sum. Theol., I, q. 92, a. 1 ad 3). Este incordio de índole ético tiene soluciones metafísicas y de teología natural: $1^{\text {a }}$ ) El mundo (el universo) creado sería tan inconcluso como incompleto, y en el caso que se está tratando, faltaría algo que lo complete, una mujer corpóreamente existente. $2^{\mathrm{a}}$ ) El bien común es superior al bien particular, 
está por encima de la mujer en su condición corpóreo existencial, pues ésta es necesaria en orden a la conservación de la especie, que es un bien evidentemente superior a la ocasión de pecado, que pueda darse respecto del varón, según la visión del Aquinate. Además la virtus divina puede ordenar cualquier mal, en este caso la ocasión de pecado, al bien.

Estos inconvenientes (disminución corpórea, dolor y posibilidad de pecado) que recaen en el sujeto adánico quedan resueltos debidamente, y en el entramado de fondo de las soluciones prevalece la necesidad de encaminar la realidad corpórea de la primera mujer (y del primer varón) hacia el bien común de la humanidad y del universo.

\section{El poder de Dios en la producción}

Dios creó el primer cuerpo de mujer a partir de una materia preexistente: una costilla del varón. Esta creación es inmediata y no es el resultado de un proceso embrionario como en el resto de los cuerpos femeninos (Cfr. Tomás de Aquino, Sum. Theol., I, q. 92, a. 4 co.). Este cuerpo femenino ya existía en las primeras obras según las razones causales (Tomás de Aquino, Sum. Theol., I, q. 92, a. 4 ad 3), no a modo de potencia activa, sino sólo a modo de potencia pasiva, y ésta en relación con la potencia activa o 'virtus' divina (Cfr. Tomás de Aquino, Sum. Theol., I, q. 92, a.4 co. y ad 3): "Está en el poder divino el añadir o cambiar o separar algo de las cosas creadas” (Tomás de Aquino, Super Sent., lib. 2, d. 18, q. 1, a. 2 co.). El Aquinate, siguiendo a Agustín de Hipona, manifiesta una incógnita sobre si hubo cooperación de los ángeles, pero sí sabe que no participaron en la formación del cuerpo de la mujer desde el varón (Tomás de Aquino, Sum. Theol., I, q. 92, a. 4 ad 2). Este poder divino de añadir (addat) o separar (abstrahat) o cambiar (mutat) se manifiesta cuando Dios separa una materia específica del cuerpo del primer hombre y se vuelve a evidenciar cuando añade, a esta materia separada, para compensar lo cuantitativo. Y esto puede hacerlo porque:

Por parte de la materia: “ $1^{\circ}$ ) Dios, que es autor de toda realidad de la cosa, no sólo ha dado las formas y virtudes naturales a las cosas, sino también la potencia para recibir lo que Él mismo quiera hacer en la materia”. Y, por 
parte de la forma: “ $2^{\circ}$ ) Las formas existentes en el arte divino se dicen que son primordiales, en cuanto que son absolutamente primeros principios de las cosas que se producirán”. Y sigue el texto: "Mientras que las virtudes mismas puestas en la materia, por las que se siguen los efectos naturales, son llamadas razones seminales" (Tomás de Aquino, Super Sent., lib. 2, d. 18, q. 1, a. 2 co.) La razón del cuerpo de la primera mujer se encontraba seminalmente en la costilla del varón, ya que, 'Deus creavit omnia simul', y así, el cuerpo évico ya existía a modo de razón causal o seminal en el primer cuerpo de varón pero sólo según la potencia pasiva. La materia es coadyuvante en cuanto "está habilitada" o "es hábil” para recibir la acción de la poderosísima virtus divina, esta habilidad se denomina apetito de la materia e incoación de la forma (Tomás de Aquino, Super Sent., lib. 2, d. 18, q. 1, a. 2 co.; cfr. Super Sent., lib. 2, d. 12, q. 1, a. 4 co; Super Sent., lib. 2, d. 12, q. 1, a. 5 expos; Super Sent., lib. 2, d. 34, q. 1, a. 5 co.; Sum. Theol. I, q. 48, a. 4 co.; y De veritate, q. 12, a. 1, ad 1). "Por consiguiente, existió el cuerpo de la mujer en las primeras obras según las razones causales, no en cuanto a la potencia activa, sino sólo según la potencia pasiva, en orden a la potencia activa del Creador" (Tomás de Aquino, Sum. Theol., I, q. 92, a. 4 ad 3).

\section{El influjo teológico}

El influjo teológico en la concepción filosófica de Tomás de Aquino en este punto es muy marcado, ya que, según él, el primer cuerpo, fue tomado ex cos o ex vir y no ex capite ni ex pedibus, o mejor aún: de latere, del costado del varón. El influjo se evidencia por la analogía que establece el Aquinate: así como del costado de Cristo (ex latere Christi) surgen agua (que significa el bautismo que lava del pecado) y sangre (que significa la eucaristía, y los demás sacramentos, que redimen del pecado), y por esto se instituye la Iglesia; así, análogamente, del costado de Adán (de latere Adae) surge Eva (Tomás de Aquino, Super Sent, lib. 4 d. 28 q. 1 a. 4 expos.; Sum. Theol., I, q. 92, a. 3 co.; Sum.Theol., III, q. 62, a. 5 co.; Sum.Theol., III, q. 62, a. 5 co.; Catena in Mt., cap. 26 1. 8.; cfr. Super Sent., lib. 2 d. 18, q. 1 pr.). No es objeto de este estudio los detalles y pormenores teológicos, pero basten éstos 
para hacernos cargo de la mente de Tomás de Aquino en el momento de explicar la formación del cuerpo évico del costado (que tiene costillas) del cuerpo adánico.

El Aquinate afirma su posición desde lo religioso y específicamente desde la fe católica: "Entre los católicos no cabe duda que la mujer fue hecha de la costilla del varón, aunque los judíos fabulen muchas cosas sobre esto" (Tomás de Aquino, Super Sent., lib. 2 d. 18, q. 1, a. 1 co.). Para Tomás no caben dudas: el cuerpo de Eva se tomó de Adán, literalmente hablando. No obstante, hoy, la literalidad de la exégesis bíblica, en torno a los pasajes que se refieren a la creación del primer cuerpo femenino, ha sido ya abandonada. El magno esfuerzo del Aquinate en buscar explicaciones de razón merece gran consideración y deferencia por parte del hombre actual. El Tomás de Aquino, filósofo, busca afanosa e incesantemente repuestas filosóficas a planteamientos religiosos.

Conviene, en lo que se ha tratado, extraer y separar el contenido de razón dejando de lado, con respeto y mucho cuidado, todo aquello que le sobrepasa. Y así, resaltar el tratamiento y estudio que hace de Dios como autor e institutor de toda la naturaleza, es decir, un Dios capaz de dominar la materia de un modo absoluto, de moldearla y malearla a su entera voluntad y de no estar sujeto a ninguna determinación natural: Dios separa y adiciona a voluntad desde una mirada sapiencial y providencial, sólo debe resguardarse de cualquier contradicción a la que se pueda llegar en las distintas argumentaciones posibles, pues, Dios lo puede todo menos lo imposible. Asimismo, el Aquinate, muestra una preocupación permanente por comprender lo menos inteligible, la materia, que es pura pasividad y algo totalmente indeterminado pero determinable por la virtus divina: "Sólo Dios, institutor de la naturaleza, puede dar el ser a las cosas prescindiendo del orden natural, se sigue que sólo Él pudo formar al varón del barro y a la mujer de una costilla del varón” (Tomás de Aquino, Sum. Theol., I, q. 92, a. 4 c.).

La concepción a la que se arriba acerca del primer cuerpo de mujer y del cuerpo de la mujer en sí, de alguna manera, importuna la condición femenina: la mujer queda sujeta al varón pues de éste es tomada, de éste viene, es decir, su existencia depende de la existencia anterior del cuerpo 
varonil: el cuerpo varonil es causa del femenino que es su efecto, de donde se concluye que el varón es cabeza de la mujer (vir caput est mulieres) y por esto, ella le está sujeta. Estas consideraciones intervendrán en la concepción del matrimonio y en sus propiedades, sobre todo la de indisolubilidad; como así también en la diversidad posible de estados religiosos.

Tomás de Aquino, en el Comentario a la Primera Carta a los Corintios, glosando el capítulo que se refiere al matrimonio y a la virginidad, y en la cuestión 92 de la I Parte de la Suma Teológica, que se ocupa del origen de la mujer, explica que, no se tomó de los pies para impedir que la mujer sea tomada como sierva (ancilla) del varón y así evitar que éste la desprecie; y tampoco se tomó de la cabeza del varón para impedir que la mujer sea señora ('domina') del varón y domine sobre él (neque enim mulier debet dominari in virum): "Respondo que fue conveniente que la mujer fuera formada de la costilla del varón. Primero, para significar que entre ambos debe haber una unión social. Pues la mujer no debe dominar al varón (1 Tim 2,12); por lo cual no fue formada de la cabeza. Tampoco debe el varón despreciarla como si le estuviera sometida servilmente; por eso no fue formada de los pies" (Tomás de Aquino, Sum. Theol., I, q. 92, a. 3 co.). Por esto, fue tomada del costado: para que coadyuve al varón en todo lo referido a la vida doméstica y matrimonial, para que haya unión social entre varón y mujer (inter virum et mulierem debet esse socialis coniunctio), y para que sea tomada como su compañera (socia): "De donde, (el cuerpo) de la mujer no está formado de los pies (del cuerpo) del varón para que no sea tomada como su sierva, ni tampoco de la cabeza (del cuerpo) para que no sea tomada como su señora, sino del costado para que sea tomada como compañera" (Tomás de Aquino, Super I Cor., cap. 7 1. 1).

Tomás de Aquino comentando a Aristóteles, como ya se ha dicho, ha hablado de dos "razones evidentes por sí mismas" (Tomás de Aquino, Super Sent., lib. 2, d. 18, q. 1, a. 1 ad 1). La primera razón evidente se refiere a que la unión social entre un varón y una mujer ha de ser de trato con dulzura. La segunda razón evidente se refiere a que este trato del varón para con la mujer es más considerado que cualquier otro (Cfr. Aristóteles, Ética, Libro VIII, capítulo XII, 1162a). Nótese que no dice entre esposo y esposa, pues el 
Aquinate escribe varón y mujer (mas y femina), lo cual convierte estas razones evidentes por sí en razones que exceden el marco de la unión matrimonial, pues incluyen a todo varón y a toda mujer en unión social.

\section{Conclusión}

El primer cuerpo femenino o el cuerpo de Eva, la primera mujer viene 'del' varón, depende 'de' otro. Estas afirmaciones respecto del cuerpo femenino permiten extraer conclusiones fundamentales respecto al modus vivendi femenino y de su relación de sujeción al varón que manifiesta cierta desigualdad esencial con éste, generando, de alguna manera, cierta e impropia inferioridad comparativa. La institución del cuerpo femenino da lugar, pues, a una gran variedad de consecuencias que sobrepasan la consideración estrictamente filosófica pero que incide en las situaciones culturales que una mujer vive a diario. Algunas consecuencias derivan en afirmaciones que merecen una atención y estudio especial que aquí no corresponde tratar.

Metafísica o creacionalmente, el primer cuerpo femenino, o cuerpo de Eva, viene ‘del’ varón y ‘de’ Dios. En cambio, en el varón hay una doble consideración: si se refiere al primer cuerpo del varón o el cuerpo de Adán. El del primer hombre viene directamente 'de’ Dios; y si se refiere al cuerpo del varón en sí, éste se genera en un acto perfecto de concepción y transmisión de la virtus formativa sin irregularidad alguna que interfiera en este proceso, en cambio, el cuerpo de la mujer depende 'de' otros: de un varón y de Dios, y en cuanto al cuerpo en sí de la mujer, éste se genera como un acto fallido en la concepción y transmisión de la virtus por múltiples motivos.

Las afirmaciones respecto del cuerpo femenino permiten extraer conclusiones fundamentales respecto al modus vivendi femenino y de su relación con el varón. Es una relación de inigualdad: la mujer debe sujetarse al varón. La sujeción o sumisión en sí, dice el Aquinate, puede ser de dos maneras posibles:

- por un lado la servil, cuando el señor se sirve de un súbdito para su utilidad;

- por otro lado, la económica o civil: el señor se sirve del súbdito para 
utilidad de los mismos. Según este segundo tipo de sumisión la mujer está 'naturalmente' sometida al varón, que además tiene mayor discernimiento. Esencialmente inigual es la mujer respecto del varón, inigualdad que se expresa en inferioridad comparativa.

Además, por otro lado, un sujeto humano es siervo de otro en cuanto al cuerpo, y no en cuanto al alma que permanece libre (Tomás de Aquino, Sum. Theol., II II, q. 104, a. 6 ad 1).

El Aquinate enumera tres tipos de trabajo servil:

- uno referido al hombre cuando sirve al pecado, es decir, es siervo del pecado, de donde toda acción pecaminosa es servil. Es una servidumbre que hace referencia directamente a lo religioso.

- Una segunda se refiere cuando un hombre sirve a otro hombre, servidumbre que no es en cuanto al alma sino en cuanto al cuerpo. Y aquí estas obras o trabajos se llaman corporales (Tomás de Aquino, Sum. Theol., II II, q 104, a 5 co.)

- Y una tercera se refiere cuando un hombre sirve a Dios.

Importa aquí la segunda servidumbre, pues la mujer está sujeta al varón en este sentido: no sólo está sujeta naturalmente (naturaliter) al varón por tener éste más discernimiento (in homine magis abundat discretio rationis), sino porque también es superior corporalmente, lo cual obliga a la mujer (y a otros varones menos sabios) a obedecer en cuanto a las acciones corpóreas externas. El agente es más noble que el paciente, de donde la mujer, por su condición corpórea, es naturalmente inferior al hombre en poder y en dignidad (Rossi 1991, 108), por eso no fue producida en la primera creación (Tomás de Aquino, Super Sent., lib. 2, d. 20, q. 1, a. 2 co.).

Es cierto que, la literalidad de las Escrituras y las nociones biológicas y aristotélicas aceptadas en el siglo XIII, respecto de la producción de la primera mujer, están hoy en gran parte ya refutadas, de donde, y en consecuencia, también algunas de sus afirmaciones filosóficas y teológicas construidas a partir de éstas. No obstante, esto no debe constituirse en un pretexto para archivar de plano y definitivamente todas las afirmaciones de Tomás de Aquino sobre el cuerpo de la mujer (cfr. Rossi 1991, 106). El magnífico esfuerzo del Aquinate en justificar filosóficamente la existencia de 
la primera mujer merecen y mueven a otras reflexiones referidas al carácter en sí de su contenido y a sus consecuencias en la actualidad.

\section{Bibliografía}

Alby, Juan. 2007. "La medicina medieval y la filosofía tomista del cuerpo." XXXII Congreso Internacional de la Sociedad Tomista Argentina: Filosofía del cuerpo: Artículo 22.

Archideo, Lila Blanca. 1991. "Bases para una antropología femenina en Santo Tomás.” Atti del IX Congresso Tomistico Internazionale: 91-104.

Archideo, Lila Blanca. 2004. "Un aporte al humanismo cristiano: la mujer y la amistad. Sus bases en Santo Tomás de Aquino." Atti del Congresso Internazionale su l'umanesimo cristiano nel III milennio: la prospettiva di Tommaso d'Aquino: vol. 1, 287-293.

Argüello, Santiago. 2005. Posibilidad y principio de plenitud en Tomás de Aquino. Pamplona: Eunsa.

Balmaseda Cinquina, María Fernanda. 1995. "El neofeminismo y la concepción de la mujer según Santo Tomás.” Philosophica 18: 181-201.

Gilson, Etienne. 1951. El tomismo. Introducción a la filosofía de Santo Tomás de Aquino. Buenos Aires: Desclée, de Brouwer.

Hartel, Joseph Francis. 1993. "Femina ut imago Dei, In the Integral Feminism of St. Thomas Aquinas.” Analecta Gregoriana 269: 83-89.

Horvat, Sasa. 2017. "Neuroscientific findings in the light of Aquinas' understanding of the human being." Scientia et Fides 2 (2017): 127-153.

Oliboni, Melissa. 1995. Anima e corpo in Tommaso d'Aquino: una rilettura. Recanati: Editore Leopardi.

Popik, Kristine Mary. 1979. The Philosophy of Woman of St. Thomas Aquinas. Rome: Ed. Pontifical University of St. Thomas Aquinas.

Rossi, Teodora. 1991. "Il corpo muliebre nell'articolo 1 della q. 92, I pars." Studi Tomisti 42: 105-110.

Tomás de Aquino. 1988. Suma de Teología. Madrid: Biblioteca de Autores Cristianos, 5 Tomos http://hjg.com.ar/sumat/ (31.03.13).

Tomás de Aquino. 2005. Comentario a las Sentencias de Pedro Lombardo, Libro II, La formación de la mujer, Volumen II/1 La creación: Ángeles, seres corpóreos, hombre. Pamplona: Eunsa.

Tomás de Aquino. Corpus Thomisticum. http://www.corpusthomisticum.org/ (31.03.13) 